\title{
Vriesea piscatrix (Bromeliaceae): uma nova epífita da Serra do Cipó, Minas Gerais, Brasil
}

\author{
Leonardo M. Versieux ${ }^{1,2}$ e Maria das Graças Lapa Wanderley ${ }^{1}$
}

Recebido: 04.06.2009; aceito: 30.07.2009

\begin{abstract}
Vriesea piscatrix (Bromeliaceae): a new epiphyte from Serra do Cipó, Minas Gerais, Brazil). Vriesea piscatrix, a new species related to Vriesea guttata G. Lodd. is described and illustrated. So far it is endemic to the montane forest patches occurring scattered in "campo rupestre" vegetation of Serra do Cipó.

Key words: grasslands, Espinhaço Range, Tillandsioideae
\end{abstract}

RESUMO - (Vriesea piscatrix (Bromeliaceae): uma nova epífita da Serra do Cipó, Minas Gerais, Brasil). Vriesea piscatrix, uma nova espécie relacionada à Vriesea guttata G. Lodd. é descrita e ilustrada. O novo táxon é, até o momento, endêmico da Serra do Cipó, ocorrendo em matas nebulares distribuídas em meio ao campo rupestre.

Palavras-chave: campo rupestre, Serra do Espinhaço, Tillandsioideae

\section{Introdução}

O gênero Vriesea Lindl. é o mais rico em espécies entre as Bromeliaceae de Minas Gerais (Versieux \& Wendt 2006, 2007), com diversas adições recentes para áreas de campos rupestres (e.g. Versieux 2008; Versieux \& Wanderley 2008). Trabalhos de campo, visando à conclusão da monografia das Tillandsioideae (Bromeliaceae) da Serra do Cipó, Minas Gerais, permitiram o reconhecimento de uma nova espécie, que é descrita a seguir.

\section{Resultados e Discussão}

Vriesea piscatrix Versieux \& Wand. sp. nov. TIPO: BRASIL. Minas Gerais: Santana do Riacho, Serra do Cipó, capão de mata em campo rupestre,

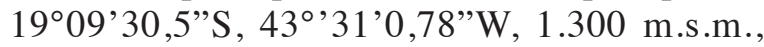
M.G.L. Wanderley, L.M. Versieux, A.M. Calvente \& R.B. Louzada 2475, 10-XII-2005, fl. (holótipo $\mathrm{SP}$, isótipos NY, RB).

Figuras 1-2

Species nova Vrieseae guttatae G. Lodd. similis, sed laminis foliorum triangularibus, confertim cinereis lepidotis, leviter carnosis, inflorescentia simplici vel ramosa differt.

Epífita, ca. $25 \mathrm{~cm}$ alt., caule reduzido; roseta ca. 24 cm compr., 34 cm diâm., infundibuliforme. Folhas
10-15, densamente cinéreo-lepidotas em ambas as superfícies, canaliculadas, subcoriáceas; bainha 6,5-8 cm compr., 4-5,2 cm larg., oval, densamente castanho-lepidota em ambas as faces; lâmina $15-19 \mathrm{~cm}$ compr., 1,5-2 cm larg., linear-triangular a triangular, recurvada, ápice agudo. Brácteas do pedúnculo: as proximais verdes com ápice vermelho-rosado; as distais 5,5-6 cm compr., ca. 1,5 cm larg., maiores que os entrenós, oblongo-lanceoladas, inconspicuamente aristadas, vermelho-rosadas com ápice esverdeado, imbricadas. Brácteas primárias semelhantes às do pedúnculo. Brácteas florais 3,1-4,2 cm compr., 1,7-2,3 $\mathrm{cm}$ larg., tão longas quanto ou menores que as sépalas na antese, vermelho-rosadas com o ápice verde. Inflorescência simples ou com até cinco ramificações, nutante. Flores dísticas. Sépalas ca. 2,6 cm compr., ca. $1 \mathrm{~cm}$ larg., elípticas, verde-claras; pétalas 3,8-4,2 cm compr., ca. 0,7 cm larg., oblongas, ápice obtuso, amarelas; apêndices petalíneos 1-1,4 cm compr., ápice obtuso. Estames ca. 4,5 cm, exsertos. Pistilo ca. 5,5 $\mathrm{cm}$ compr., ovário verde. Estigma ca. $2 \mathrm{~mm}$ diâm., lâmina-convoluta. Cápsula e semente não vistas.

Esta nova espécie de Vriesea é próxima de $V$. guttata, em razão de semelhanças na morfologia floral, inflorescência nutante e por possuir folhas com pequenas máculas arroxeadas acima da bainha. Entretanto a lâmina foliar de forma triangular com ápice agudo e com denso indumento (vs. lâmina

1. Instituto de Botânica, Caixa Postal 3005, 01061-970 São Paulo, SP, Brasil

2. Autor para correspondência: lversieux@yahoo.com.br 

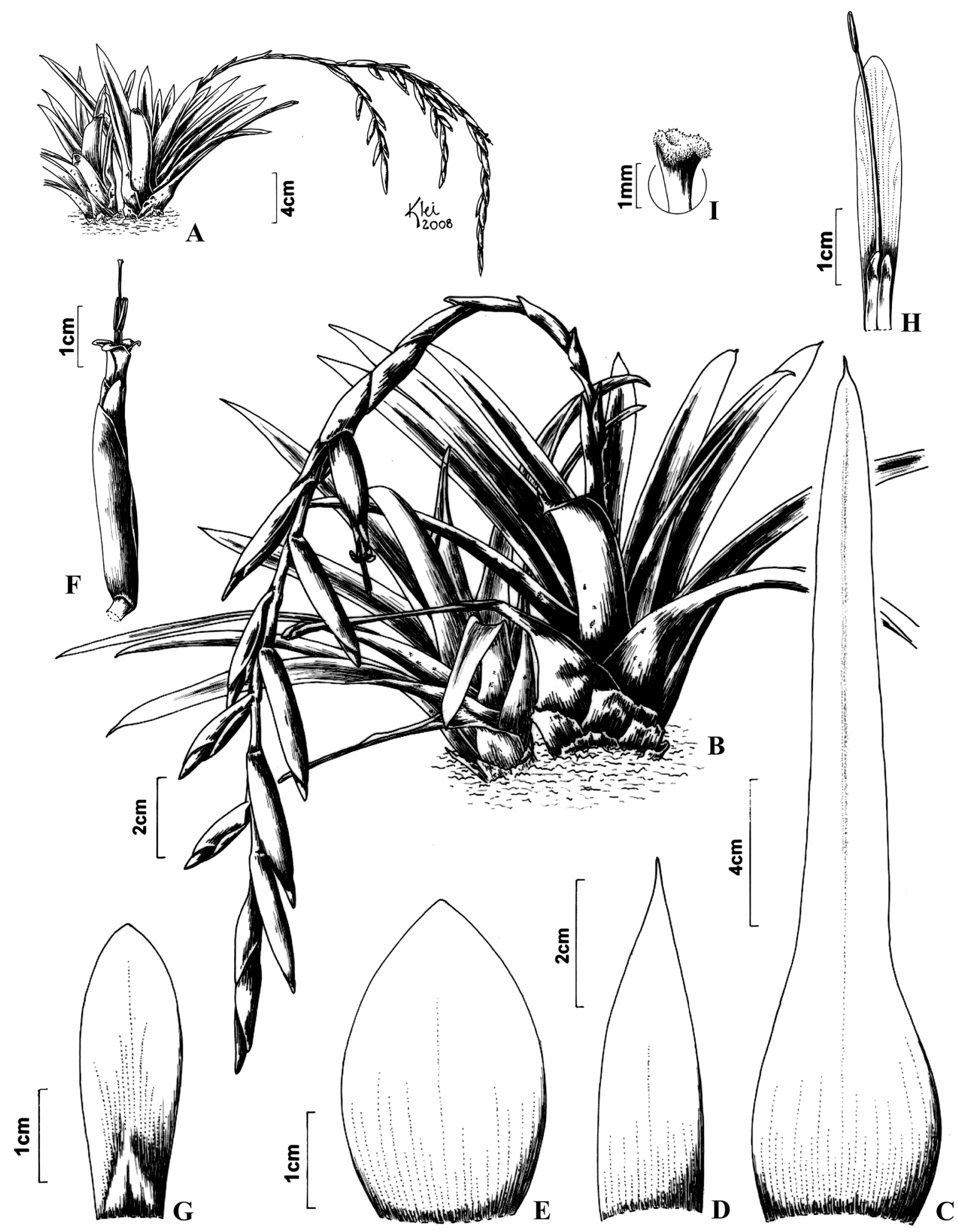

Figura 1. Vriesea piscatrix. A-B. Hábito de indivíduos com inflorescência composta e simples. C. Folha.D. Bráctea peduncular. E. Bráctea floral. F. Flor. G. Sépala. H. Pétala com estame antipétalo. I. Estigma do tipo lâmina-convoluta.

Figure 1. Vriesea piscatrix. A-B. Habit of individuals with compound and simple inflorescences. C. Leaf. D. Bract of the peduncle. E. Floral bract. F. Flower. G. Sepal. H. Petal with antipetalous stamen. I. Convolute-blade type stigma. 


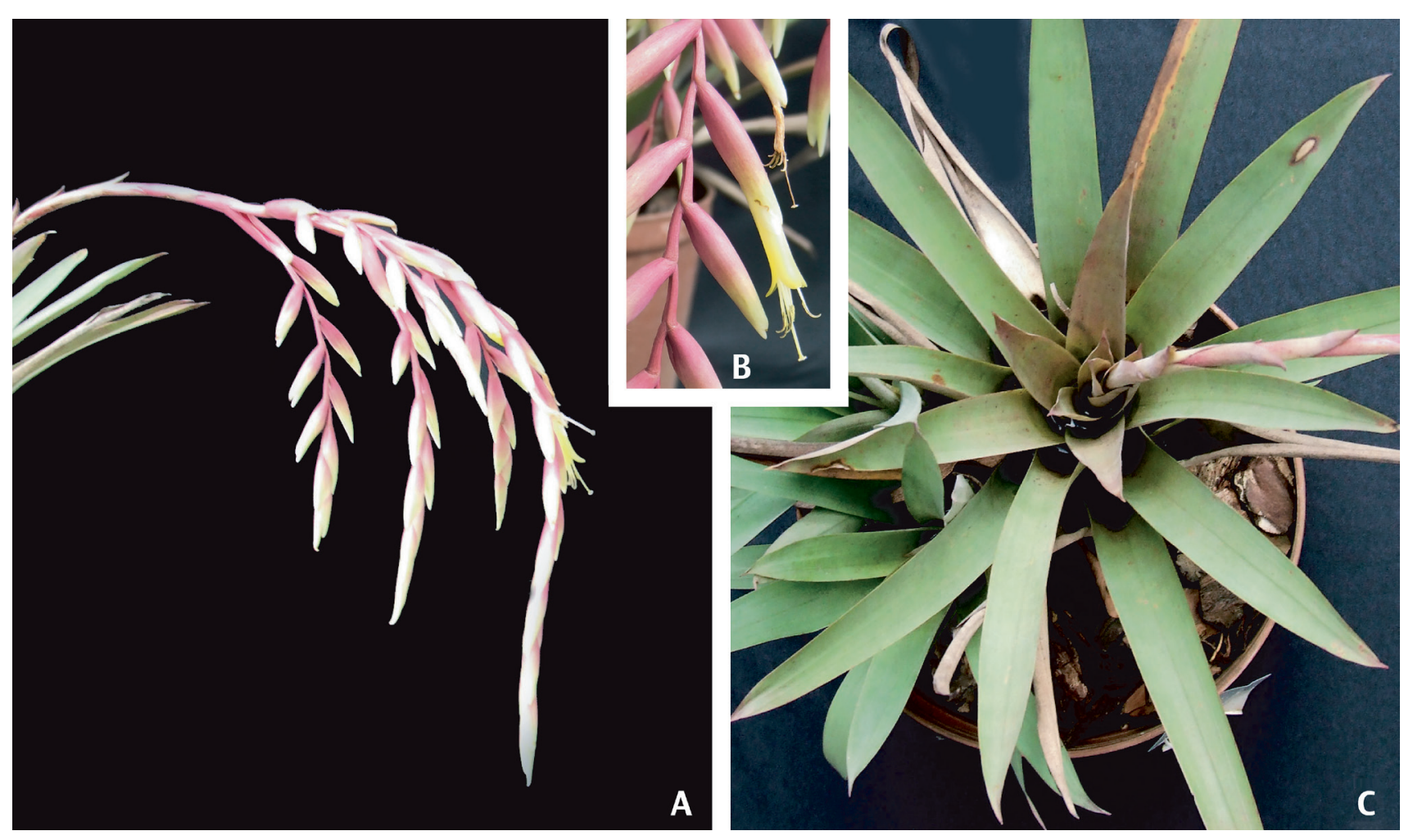

Figura 2. Vriesea piscatrix. A. Inflorescência. B. Detalhe da flor. C. Roseta (vista de cima). Fotos: L.M. Versieux.

Figure 2. Vriesea piscatrix. A. Inflorescence. B. Flower detail. C. Rosette (view from above). Photos: L.M. Versieux.

ligulada com ápice arredondado, esparsamente lepidota), a inflorescência que pode ser simples ou composta (vs. simples), o maior espaçamento entre as flores e as brácteas florais não-pulverulentas presentes na nova espécie facilitam sua distinção de V. guttata. Além disso, as folhas da nova espécie apresentam poucas máculas arroxeadas acima da bainha, uma ou duas nervuras proeminentes, a lâmina é levemente suculenta e o hábito geralmente é menor. Em $V$. guttata, as folhas são densamente maculadas de roxo em toda a sua extensão, não apresentam nervuras proeminentes tampouco são levemente suculentas e as plantas são mais robustas. Vriesea guttata é frequentemente confundida com V.pardalina Mez nas coleções de herbário, sendo frágeis as características empregadas em suas distinções, como o grau de exposição da raque na inflorescência, posição da bráctea floral e seu tamanho em relação ao das sépalas (Smith \& Downs 1977). Essas características são dependentes do estágio de desenvolvimento da inflorescência, dificultando a identificação. É possível que $V$. pardalina seja um sinônimo de $V$. guttata, que é o binômino mais antigo e aqui adotado para comparação com a nova espécie.

Vriesea piscatrix é conhecida de apenas um capão de mata no topo da Serra do Cipó, onde cresce como epífita acima de $5 \mathrm{~m}$ do solo. Apresenta aspecto geral delicado e ornamental. O epíteto-específico faz alusão à figura de uma pescadora, que pode ser imaginada no formato perfeitamente arqueado do pedúnculo e na inflorescência nutante.

Medidas visando à conservação da espécie são necessárias, uma vez que só foi coletada em área sofrendo processo de desmatamento, fora dos limites do Parque Nacional da Serra do Cipó.

\section{Agradecimentos}

Ao Dr. Tarciso Filgueiras pela correção da diagnose latina. À Fapesp pela bolsa de doutorado concedida ao L. M. Versieux e ao CNPq pela bolsa de produtividade em pesquisa concedida à M. G. L. Wanderley. Ao Klei Sousa pela ilustração. 


\section{Literatura citada}

Smith, L.B. \& Downs, R.J. 1977. Tillandsioideae (Bromeliaceae). Flora Neotropica Monograph 14, Part II. Hafner Press, New York.

Versieux, L.M. 2008. Checklist and one new species of Bromeliaceae from Pico do Itambé, Minas Gerais, Brazil. Botanical Journal of the Linnean Society 158: 709-715.
Versieux, L.M. \& Wendt, T. 2006. Checklist of Bromeliaceae of Minas Gerais, Brazil, with notes on taxonomy and endemism. Selbyana 27: 107-146.

Versieux,L.M.\& Wendt,T.2007. Bromeliaceae diversity and conservation in Minas Gerais, Brazil. Biodiversity and Conservation 16: 2989-3009.

Versieux,L.M.\& Wanderley, M.G.L. 2008. A new species of Vriesea Lindl. (Bromeliaceae, Tillandsioideae) from serra da Canastra, Minas Gerais State, Brazil. Acta Botanica Brasilica 22: 71-74. 